\title{
Minute Times Gram Per Milliliter Per Gram
}

National Cancer Institute

\section{Source}

National Cancer Institute. Minute Times Gram Per Milliliter Per Gram. NCI Thesaurus.

Code C112336.

Minutes times grams per milliliter, divided by grams. 